\title{
Addressing Mental Health Epidemic among University Students via Web-based, Self-Screening, and Referral System
}

\author{
V.D.Kulkarni, Tanuja Gondkar, Gunjan Singh, Aditi Gulunjkar
}

\begin{abstract}
The prevalence and severity of mental health problems in college and university communities are alarming. How-ever, the majority of students with mental disorders do not seek help from professionals. To help students assess their mental conditions and encourage them to take an active role in seeking care, we developed a web-based self-screening, referral, and secure communication application. The proposed system will do the self screening of the student by asking them question in the area of anxiety, depression, attention deficit disorder, alcohol use, eating disorder. If system found any student with mental disorder then that student will be refer to doctor for further checkup.
\end{abstract}

Index Terms: College, Internet, mental health, referral, screening, university, World WideWeb.

\section{Introduction}

THE 2007 incident at Virginia Tech, Blacksburg, in which a student with a serious mental illness killed 32 people and himself and other recent incidents (e.g., one at Northern Illinois University, DeKalb, in 2008) has created a high level of public awareness of mental health conditions among college and university students. As a result, the urgent need to address the mental health problems among students was identified, and some progress has been made, e.g., increasing mental health services, actively informing students of these services, and setting up teams to identify troubled students ahead of time. Many college students are in poor mental health, and common mental health issues from which they suffer include depression, anxiety, abuse of alcohol, and other substance use disorders. The prevalence and severity of mental disorders among the students have been continuously growing. Recent studies found that more than $40 \%$ of U.S. students become depressed during their four years in college and that more than $15 \%$ have clinically significant depressive disorders. In the last 20 years, the likelihood of a college student suffering depression has more than doubled, and suicidal ideation has tripled . However, the majority of students do not seek professional help for their mental health conditions. Upto $85 \%$ of students with positive screens for mental disorders do not receive any treatment from professionals even though many universities provide counseling free of charge As a result, there is a significant delay, about 11 years, between the onset of mental disorders and receiving proper treatments. Earlier studies identified factors associated with students not receiving treatment, including lack of problem recognition and perceived need, delayed time to an appointment, lack of time, financial constraints, privacy concerns, and stigma associated with treatment. Considering the number of students who may benefit from professional help, it is imperative that universities take a more proactive role in offering effective mental health outreach and treatment services to their students.

With the widespread availability and adoption of information and communication technology, webbased computerized screening and self-help intervention have been attempted as a more accessible delivery option. Internet-based screening is reported to be reliable and effective in identifying individuals with common mental health problems in college students, including depression, anxiety disorders, and alcohol dependency. Brief feedback (e.g., screening results and/or recommendations) is effective in managing these problems. Computerized tools could attract potential patients to screen themselves improve recognition of the disorders and motivate them to be more active in receiving appropriate help from professionals. However, screening alone is insufficient for effective management and treatment of mental health conditions. To be more effective, it is desirable that screening be tightly integrated with accessing professional services so that after the mental health need is identified via screening, the students can act on the need in the same session.

\section{Existing System}

While studying Existing system we identified factors associated with students that student not receiving treatment, because of :

a)Lack of problem recognition and perceived need.

b)Delayed in time to an appointment.

c) Lack of time to meet the doctor and do the checkup.

d)Financial constraints.

e)Privacy concerns and stigma associated with treatment. 
By considering these factors we reach on the conclusion that the existing system is not efficient for the student who has time constraints and who are seeking for such system which will maintain their privacy.

\section{Proposed System}

The system under the name of "Addressing Mental Health Epidemic Among

University Students via Web-based, Self-Screening, and Referral System" is designed to perform the Self Screening of University Student to find out their mental condition. The Proposed system help students assess their mental conditions and encourage them to take an active role in seeking care, we developed a web-based self-screening, referral, and secure communication system. The proposed system has the following four main functions

a) Offer web-based, self-screening tools to students

b) Enable students to refer themselves to the mental health center to schedule an appointment.

c) Provide a web based repository to store and share Personal Health Information (PHI)

d) Allow students to communicate with care professionals via secure and asynchronous messaging.

\section{Contribution work}

1) Data will be sending to server in encrypted format.

2) Facility to take appointment of private doctor.

3) Mailing facility will be provided to user to send the email.

4) User can check college events.

5) College admin can see the report about student in graphical format.

\section{Operating Environment}

a) $\mathrm{S} / \mathrm{W}$ Specification

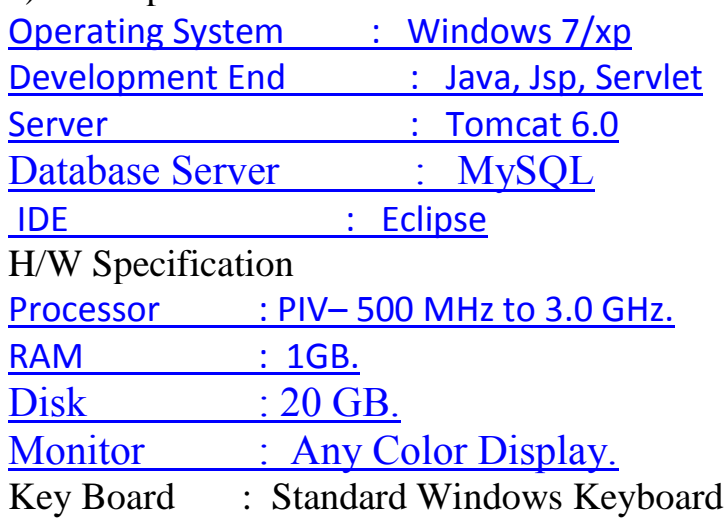

\section{User Classes And Characteristics}

The system consists of three main components:

1) Personal health information management system (PHIMS)

2) Facilitated accurate referral management system (FARMS)

3) Mental health information management system (MHIMS).

\section{System Implementation Plan}

Module1:

$>$ Develop the Web Application with Registration/Login module for Student.

$>$ In this module the student will successfully login to the admin.

$>$ From the the admin the user i.e the student has to give up the screening test.

$>$ In the screening test a set of questions will be stored in the database which has to be cleared by the students.

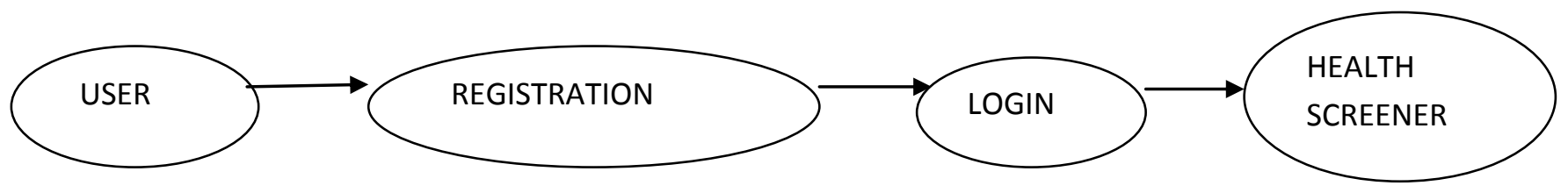

Module2. 
$>$ In this module all question will be gathered and group wise place in database.

$>$ User perform self screening.

$>$ Once the user is login successfully he/she will have to go screening test which requires the questions.

$>$ So for that purpose this module will implement the questionary section where the questions will be gathered.

$>$ And this questions will be holding the threshold value each which will make it easy for gaining the result.

Module3.

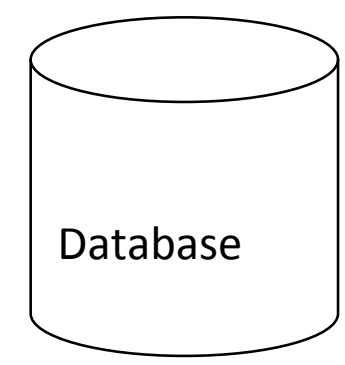

$>$ In this module screening result will be evaluate and find out whether the student is mental or not.

$>$ Here the answers obtained and the threshold value stored will be compared.

$>$ Accordingly Email sending facility will be completed.

$>$ In this section the respective student will be judged whether treatement is required or not.

$>$ Based on the answers given by the student result will be evaluated.
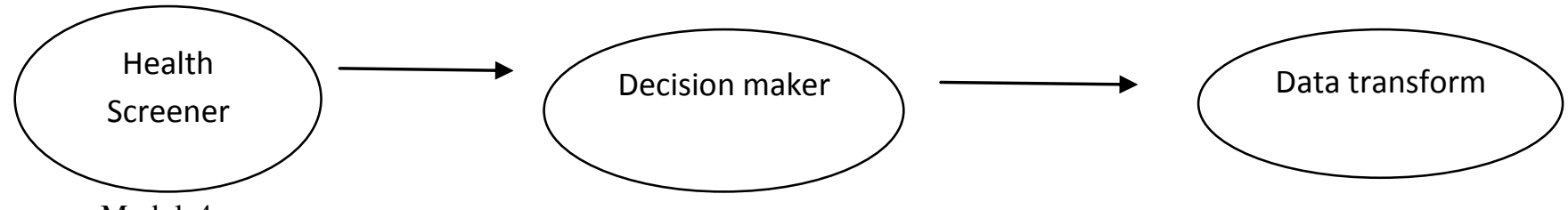

Module4.

$>$ Based on the screening test results mental student will refer to doctor.

$>$ Doctor will able to see the student screening data.

$>$ Doctor will treat the student according to the results got from the screening test.

$>$ If require more treatement more observation will be done and if the condition is less complicated then soon the student will be cured.

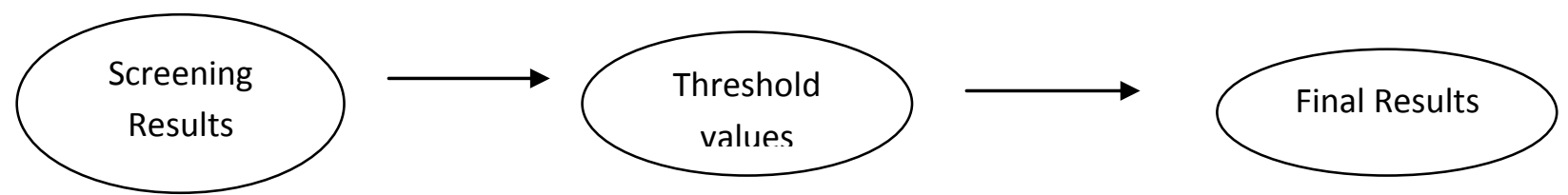

\section{Block Diagram of the system:-}

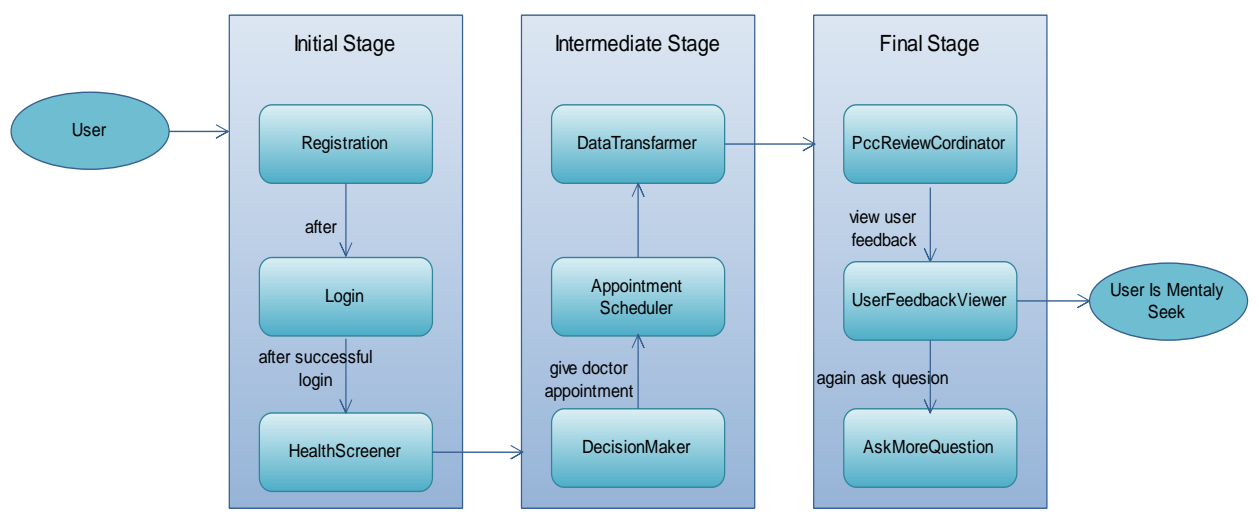

\section{1)Initial Stage:-}

a) Registration :-In this section the user has to sign up or do the registration that he or she is a valid user. Without Registration the login is not possible or the user won't be able to get the treatment. 
b) Login :-After doing the registration it will be confirm that the user is valid for the usage of the system. And the user can create the account for the further usage or for further treatment.

C) Health Screener:-The next step after the login is the screening test where the user has to give the screening test. In the screening the Questions related to the health or related to other activities of the user will be asked to them. And all this answers will be stored in the Database.

\section{2) Intermediate Stage:}

a) Decision maker:- Here the data which we got in the previous step will be given to the decision maker where they will diagnose whether the patient needs to be further treated or not. If the result is normal then no further treatment will be given to the user.

b) Appointment Scheduler:- This will schedule the appointment with the respective doctor.and the student can see their respective doctors and if they want they can change the docter.

c) Data Transformer:- This will take the data of the student and will mail it to the docter.All the relevant documents and reports will be provided by the student if he has any.

\section{3) Final Stage:}

d) PCC Review Coordinator:- Once completed, the request is forwarded to patient care coordinators (PCCs) for processing. A PCC can exchange messages with the student via secure messaging to request additional information or provide information about the referral status. For effective triage, the system informs the PCC whether a student is screened positive or not on a specific test, but does not provide any detail. Once an appointment is scheduled with a care provider, the provider can access the information and exchange messages with the student and if necessary ask him/her to complete an additional screening test(s).

e) User Feedback Viewer:- User activities, such as information updates and retrievals, were measured from the server/database logs and the audit trail feature in the system. The logs and audit trail recorded the details of user activities, type of activities (e.g., enter, update, or delete), and the date, time, and duration of each access.

\section{System Architecture}

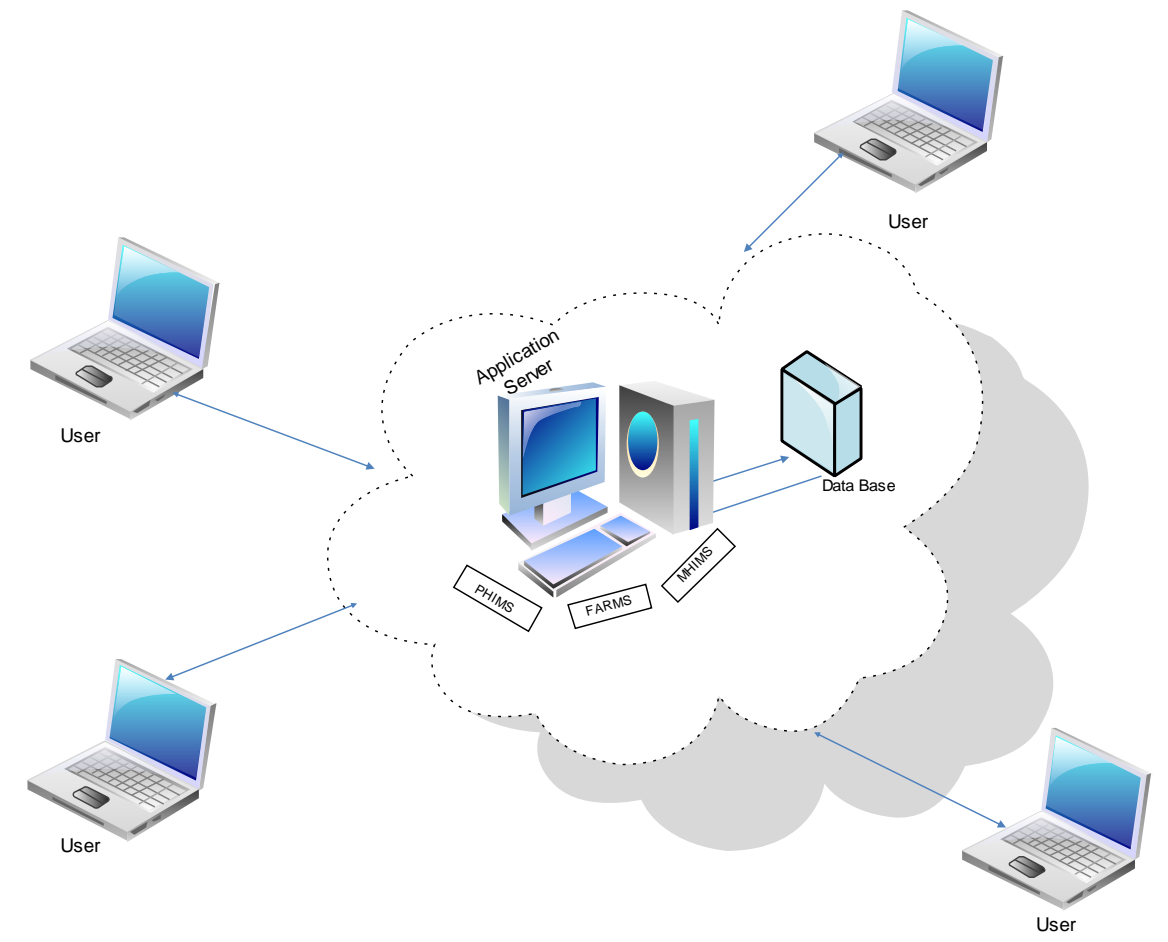

\section{Advantages}

a) Reduce the problem which is associate with the student problem recognition

b) Student no need to wait for professionals appointment.

c) Maintain privacy about user problem Personal Health Information.

d)Financial constraints can't keep user away from professionals (doctors) etc. 
e) Mailing facility is provided to user.

f) Not only for the students but also applicable for other user.

Disadvantages

a) Only the students who were scheduled for a clinic visit were invited to participate in the survey.

b) The students who did not have their appointment scheduled tend to express more negative opinions.

\section{Applications}

1) University: This system is fare enough for the students studying in the university. There is a lot of possibilities in the colleges for such type cases. Students get mentally sick due many reasons of studies, addiction and many other bad habits

2) Staff: It is also applicable for the staffs or any other worker in the university. Not only the students but also the staff of the colleges can be mentally sick and will require such kind of treatment. So for this purpose it is also applicable for the staff members.

3) Hospitals: Applicable and useful in the hospitals. The patients which have already got diagnose as mental and needs the treatment can also use this system.

\section{Results}

This system help to reduce the problem which is associated with the student problem recognition. This means that sometime student feels shy to talk to their guides or parents or their friends regarding some personal problem. So if design such system which will not only make student free but also solves his problem. Student no need to wait for professionals appointment. The university students mostly avoid going to physician due to lack of time management. So the system will help them by saving the time and kindly giving the status of their health without waste of time. So its time saving system. It also helped to maintain privacy about user problem Personal Health Information. The information provided by the student which is saved in the database maintains the privacy and provides the high security to the user data. This makes the system more reliable and safe for the usage. The system takes care about the data leakage of the data stored in database. Financial constraints can't keep user away from professionals (doctors) etc. this system is fare enough as you can login through the networking sites. So there is no constrains of the financial problems. Mailing facility is provided to user. Every time the user do not have to go to the physician for the appointment or meet regularly. It is possible to connect to them through the mailing system or by just sending the mail and discuss the problem. Not only for the students but also applicable for other user. Some professionals or the regular patients or the worker can also use this system by simply login. Only the students who were scheduled for a clinic visit were invited to participate in the survey. The students who did not have their appointment scheduled tend to express more negative opinion.

\section{Conclusion}

So this system is fare enough for the students studying in the university. There is a lot of possibilities in the colleges for such type cases. Students get mentally sick due many reasons of studies, addiction and many other bad habits. It is also applicable for the staffs or any other worker in the university. Not only the students but also the staff of the colleges can be mentally sick and will require such kind of treatment. So for this purpose it is also applicable for the staff members. Applicable and useful in the hospitals. The patients which have already got diagnose as mental and needs the treatment can also use this system. The problem of mentality is not only found in the students but it can also get caught by the workers in the companies or in the industries. So it is also useful for the other workers to get once checked for confirmation of the normality.

\section{References}

[1] American College Health Association, "National college health assessment spring 2008 reference group data report," J. Amer. Coll. Health, vol. 57, pp. 477-488, 2009.

[2] [11] K. Zivin, D. Eisenberg, S. E. Gollust, and E. Golberstein, "Persistence of mental health problems and needs in a college student population,” J. Affective Disorders, vol. 117, pp. 180-185, 2009.

[3] American College Health Association, "National college health assessment spring 2007 reference group data report," J. Amer. Coll. Health, vol. 56, pp. 469-479, 2008.

[4] R. Kadison and T. F. DiGeronimo, College of the Overwhelmed: The Campus Mental Health Crisis and What to Do about it. San Francisco, CA: Jossey-Bass, 2004.

[5] E. Kim, A. Mayani, S. Modi, C. Soh, and Y. Kim, "Evaluation of patientcentered electronic health record to overcome digital divide," Conf. Proc. IEEE Eng. Med. Biol. Soc., pp. 593-596, 2005.

[6] J. R. Fann, D. L. Berry, S. Wolpin, M. Austin-Seymour, N. Bush, B. Halpenny, W. B. Lober, and R. McCorkle, "Depression screening using the Patient Health Questionnaire-9 administered on a touch screen computer," Psychooncology, vol. 18, pp. 14-22, 2009 
[7] M.Wang, C. Lau, F. A. Matsen, and Y. Kim, "Personal health information management system and its application in referral management," IEEE Trans. Inf. Technol. Biomed., vol. 8, pp. 287-297, 2004.

[8] S. Bakken, L. Grullon-Figueroa, R. Izquierdo, N. J. Lee, P. Morin,W. Palmas, J. Teresi, R. S. Weinstock, S. Shea, and J. Starren, "Development, validation, and use of English and Spanish versions of the telemedicine satisfaction and usefulness questionnaire," J. Amer. Med. Inform. Assoc., vol. 13, pp. 660-667, 2006.

[9] R. L. Spitzer, K. Kroenke, J. B.W.Williams, and B. Lowe, “A brief measure for assessing Generalized Anxiety Disorder: The GAD7,” Archives Internal Med., vol. 166, pp. 1092-1097, 2006.

[10] E. Kim, A. Stolyar,W. B. Lober, A. L. Herbaugh, S. E. Shinstrom, B. Zierler, C. Soh, and Y. Kim, "Usage patterns of a personal health record by KIM et al.: elderly and disabled users," Amer.Medical Informat. Assoc. (AMIA) Annu. Sym. Proc., pp. 409-413, 2007. 